\title{
PIXE Analysis of Some Environmental Samples from Selected Saline Region of Bangladesh
}

\author{
M. R. Rahman, M. O. Rahman, M. A. Shariff, M. S. Uddin, M. M. Hasan, and M. A. Shameem
}

\begin{abstract}
In the present study Particle Induced X-ray Emission (PIXE) method has been used to identify the elements present in some environmental samples (soil and vegetable) in order to show the possible influence of soil in the metal absorption by the vegetables grown in saline region of Bangladesh. PIXE can detect a high number of elements with a high sensitivity (ppm range) in a simple and fast way. The samples were prepared for irradiation following conventional methodology and irradiated with $2.5 \mathrm{MeV}$ collimated protons from the $3 \mathrm{MV}$ tandem accelerator of Bangladesh Atomic Energy Commission. The X-rays emitted during irradiation from the samples were measured by HPGe detector and the acquired X-ray spectrum was analyzed by using the software GUPIXWIN. The obtained results were compared with two standard values IAEA-359 (cabbage) and IAEA Soil-7. Concentrations of some heavy metals $(\mathrm{Cr}, \mathrm{Co}$ and $\mathrm{Ni}$ ) were found above the potentially risky levels in soils; however, they accumulated in plants to a lesser amount, probably because of the physical and chemical properties of soils that prevent their conduction to vegetables. As, $\mathrm{Cd}$ and $\mathrm{Pb}$ were not found in any one of the soil and vegetable samples in the present study.
\end{abstract}

Index Terms-Elemental analysis, GUPIXWIN software, PIXE, salinity, soil and vegetables.

\section{INTRODUCTION}

Soil contamination by heavy metals has become one of the greatest world environmental problems today; Bangladesh is no exception to it. In many areas contaminated soils are a threat to the groundwater quality, and thereby to the whole biosphere [1]. The main sources of soil contamination are agriculture, industry and urban spreads. In the case of agriculture in technologically advanced countries, industrialization has brought major change to agricultural practices, including the use of chemical fertilizers, animal wastes and subsoil waters. Although these materials are not intrinsically pollutants, inappropriate use can turn them into such [2]. Salinity may also contaminate the soil since it causes unfavorable environment and hydrological situation that restrict the normal crop production throughout the year [3].

Bangladesh is a deltaic country with total area of 147,570 $\mathrm{km}^{2}$. Coastal area of Bangladesh covers about $20 \%$ of the

Manuscript received June 17, 2014; revised May 4, 2015.

M. R. Rahman and M. O. Rahman are with the Department of Physics, Jahangirnagar University, Savar, Dhaka, Bangladesh (e-mail: raafku@gmail.com, rahmanju83@gmail.com).

M. A. Shariff, M. S. Uddin, M. M. Hasan, and M. A. Shameem are with the Tandem Accelerator Facility, Institute of Nuclear Science and Technology, Atomic Energy Research Establishment, Savar, Dhaka, Bangladesh (e-mail: asad_shariff_roni@yahoo.com, md.suzauddin@yahoo.com, shameem_afd@yahoo.com). country and over $30 \%$ of the net cultivable area. Agricultural land use in these regions is very poor because of salinity which is roughly $50 \%$ of the country's average [4]. The soils of coastal areas become saline as it comes in contact with the sea water and continues to be inundated during high tides and ingress of sea water through creeks. It affects crops at the critical stages of growth, which reduces yield and in severe cases total yield is lost. Saline soils are mainly found in Khulna, Barisal, Patuakhali, Noakhali and Chittagong districts of the country. Most of the soils of these regions are moderate to strongly alkaline ( $\mathrm{pH}$ ranges from $6.0-8.4$ ), organic matter $(\mathrm{OM})$ content ranges from $1.0 \%-1.5 \%$, the cation exchange capacity (CEC) ranges from $9.4-40.6$ m.e.\%, the total nitrogen $(\mathrm{N})$ content is very poor, mostly around $0.1 \%$ and available phosphorus $(\mathrm{P})$ ranges from $15-$ 25 ppm. Widespread $\mathrm{Zn}$ and $\mathrm{Cu}$ deficiencies have been observed in the coastal regions [5].

The main source of metals in human diet is fruits and vegetables (about 73\%). Vegetables can absorb metals from soil and from water used during cultivation and contained in the airborne particles deposited on the leaves. Agricultural techniques especially the use of agricultural products such as fertilizers and pesticides are also an important source of metals for vegetables. Some metals such as $\mathrm{K}, \mathrm{Ca}, \mathrm{Mg}, \mathrm{Fe}$ etc. are important for human health; however, others can cause serious damage when ingested above a threshold as $\mathrm{Cr}, \mathrm{Cd}$, $\mathrm{As}, \mathrm{Pb}$ etc. Therefore, in order to understand the effect of metals on human health, it is important to know the contents and concentration of metals in food stuffs as well as in soils where they cultivate. Such types of study are done frequently almost all countries of the world to ensure the quality of health and life of their citizens. But still information of this topic is rare, especially when dealing with developing countries like Bangladesh.

The aim of this study was to identify the elements presents in soils and vegetables collected from different agricultural fields of Dacope, Khulna, a saline region of Bangladesh. In addition to this, the possible impact of soil in the metal involvement by the vegetables was also observed. The study area is located in southwestern part of the country where sometimes saline waterlogged happened for long time due to tropical storm like Aila, Sidr etc. The agro-chemical characteristics of soils in the study area are listed in Table I and Table II. In this work PIXE was applied for determination of elemental mass concentration. Atomic absorption spectrometry (AAS), atomic emission spectrometry (AES) or inductively coupled plasma mass spectrometry (ICP-MS) are also used for elemental analysis of soil [6] but sample preparation steps of these methods are laborious and involve risk of contamination [7]. On the other hand for the 
monitoring of metals in contaminated soils PIXE seem to have several advantages than that of other methods. The outcome of the study will help to understand the environmental pollution by soil salinity and its effect on human health of the locality mentioned above.

TABLE I: AGRo-CHEMICAL CHARACTERISTICS OF SOILS OF THE STUDY

\begin{tabular}{|c|c|c|c|c|c|}
\hline District & $\mathbf{p H}$ & $\begin{array}{c}\text { OM } \\
\boldsymbol{\%}\end{array}$ & $\begin{array}{c}\text { Total N } \\
\boldsymbol{\%}\end{array}$ & $\begin{array}{c}\text { CEC } \\
\text { m.e. \% }\end{array}$ & $\begin{array}{c}\text { P } \\
\mathbf{p p m}\end{array}$ \\
\hline Khulna & $6.2-7.9$ & $0.1-0.3$ & $0.1-0.3$ & $18.2-40.6$ & $8-36$ \\
\hline
\end{tabular}

Sources: Annual reports of BARI, BRRI, BWDB and DU of the coordinated research project on production potentials of the coastal saline soils of Bangladesh (1987-1989).

\section{MATERIALS AND METHODS}

\section{A. Sample Collection and Preparation}

A total number of 20 soil and vegetable samples were collected from different agricultural fields of Dacope, Khulna, one of the saline affected areas of Bangladesh. The vegetables were cultivated in the same area of soil samples. All the collected samples were oven dried at $60^{\circ} \mathrm{C}$, grounded by agate mortar and then pressed using hydraulic press to make pellet of $13 \mathrm{~mm}$ diameter and about $1 \mathrm{~mm}$ thickness.

\section{B. Irradiation and Data Acquisition}

The present experiment was carried out at the Tandem Accelerator Facilities Division, INST, AERE, Bangladesh Atomic Energy Commission using $3 \mathrm{MV}$ tandem accelerator. A collimated proton beam of energy $2.5 \mathrm{MeV}$ with a diameter of $2 \mathrm{~mm}$ made to fall on the sample. The integrated charge irradiation on the sample was kept in the range of 5 to 10 micro coulombs and the irradiation was performed for 5 to 10 minute to get sufficient X-ray counts.

During irradiation, the beam current was in the range of 10 to $20 \mathrm{nA}$. Individual irradiation was performed for each sample.

The X-rays emitted in the irradiation were counted using solid state detector (HPGe) associated with the necessary electronics. The detector was mounted at $45^{0}$ to the beam direction. A thin Mylar foil was placed between detector and sample for the elimination of unwanted low energy X-rays to reduce noise in counting system and also to improve the spectrum quality. Accuracy and precision of the methods were assured by analyzing certified reference materials in the same experimental conditions.

\section{Data Analysis}

The PIXE spectral data were analyzed by using GUPIXWIN software [8] package which provides non-linear fitting of the spectra and converts raw spectral data into elemental concentrations. The unknown concentration for a specific element in the analyzed sample is calculated by using the following equation [9]:

$$
C_{Z}=\frac{Y}{Y_{t} Q \varepsilon T H}
$$

where $Y_{t} \& Y$ are theoretical and experimental intensity of
X-ray respectively, $Q$ is the measured proton beam charge, $\varepsilon$ is the efficiency of the detector, $T$ is the transmission through any filters or absorbers between the target and the detector and $H$ is the hybrid parameter equivalent to the product of the geometric solid angle of the X-ray detector and any systematic calibration factor present in the PIXE set-up. $\mathrm{H}$ values as a function of X-ray energies can be measured experimentally using wide range of pure single-element standards.

\section{RESULTS AND DISCUSSIONS}

\section{A. Elements in Soil Samples}

The relative mass concentrations of ten soil samples were determined by PIXE technique. The results are presented in Fig. 1. Standard values (IAEA Soil-7) are included for comparison. A total number of 21 elements were identified among them $\mathrm{K}, \mathrm{Ca}, \mathrm{Ti}, \mathrm{Cr}, \mathrm{Mn}, \mathrm{Fe}, \mathrm{Co}$ and $\mathrm{Ni}$ were observed in all samples. Some of them $(\mathrm{K}, \mathrm{Ti}, \mathrm{Mn}$ and $\mathrm{Fe})$ are well agreed with the standard values while $\mathrm{Ca}$ found in less amount. On the other hand, heavy elements such as $\mathrm{Cr}$ (185.8-298.6 ppm), Co (592.2-882.8 ppm) and Ni (98.03-146.9 ppm) are found with high concentrations considered as potentially hazardous [10], making a more repeated monitoring needed for a future remediation. The values of $\mathrm{Cr}$ are very close to second guideline value (250 ppm) [11]. The general level of the pollution is often characterized by a contamination factor defined as a ratio of the element concentration in the samples from the polluted region to the background concentration of the same element. The ratios of concentrations (average) of heavy metals obtained in the investigated soil to IAEA Soil-7 were estimated: Cr 3.12; Mn 0.77; Fe 1.49; Co 85.17; Ni 4.69; $\mathrm{Cu} 1.45$ and $\mathrm{Zn} \mathrm{0.56}$. The highest contamination of Co was found. The contamination factors for the elements $\mathrm{Cr}$ and $\mathrm{Ni}$ are significantly large than that of $\mathrm{Fe}$. The $\mathrm{pH}$ is one of the most important parameters governing different reactions and processes in soils and also controls the behavior and bioavailability of the heavy metals in soils. For instance the motilities of different toxic elements in soils are strongly dependent on $\mathrm{pH}$. For all cationic metals, adsorption increased with $\mathrm{pH}$. In addition to bioavailable or soluble metals in soil, direct ingestion of the metals from livestock and intake in cattle will provide an exposure risk to human health. The toxicity of elements in soils depends also on the oxidation state and species formed by the element. Such studies were not performed in this work.

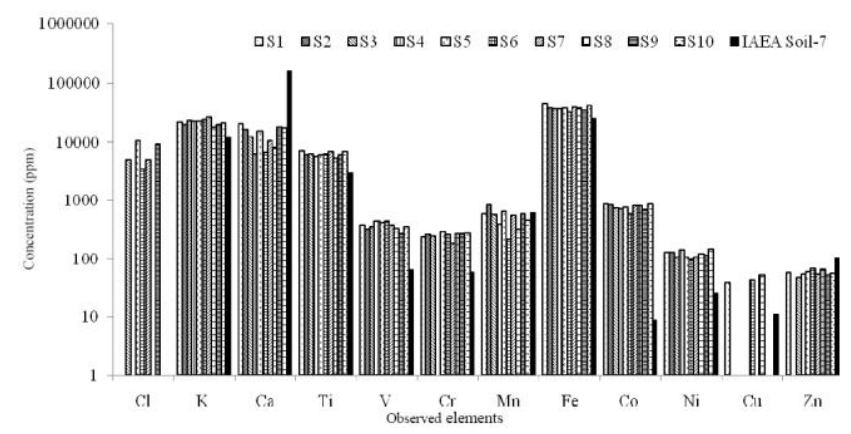

Fig. 1. Concentrations of different elements identified in soil samples.

$\mathrm{V}$ observed in soils could be from the ore or from 
anthropogenic source (burning of crude oil) [12]. Cl was found in 5 samples (S3, S5, S6, S7 and S9) with high concentrations but not present in standard value. This is due to the soils of the study area become saline as it comes in contact with the sea water and continues to be inundated during high tides and ingress of sea water through creeks and sometime saline waterlogged happened for long time. Zn was found in 9 samples with concentration less than IAEA value. $\mathrm{Cu}$ is found only in 3 samples with high levels than standard value but below potentially harmful, indicating that the soils are $\mathrm{Cu}$ deficient. For the $\mathrm{Cu}$ content there might be an influence of the larger peak of $\mathrm{Zn}$.

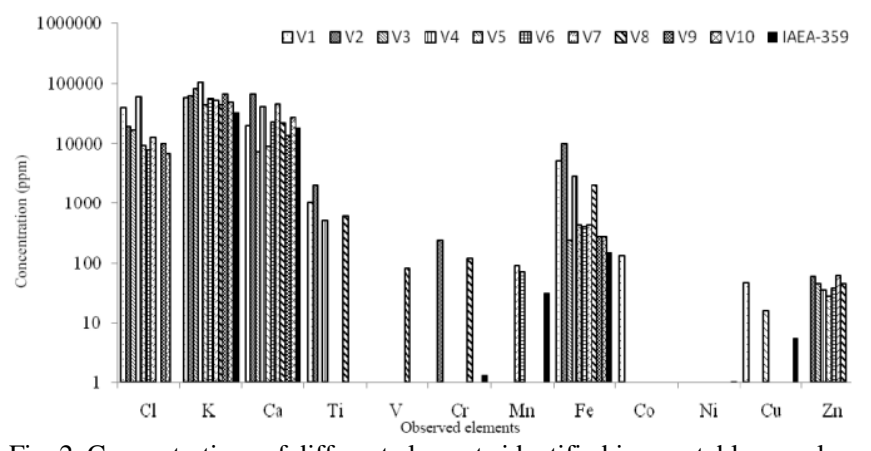

Fig. 2. Concentrations of different elements identified in vegetable samples.

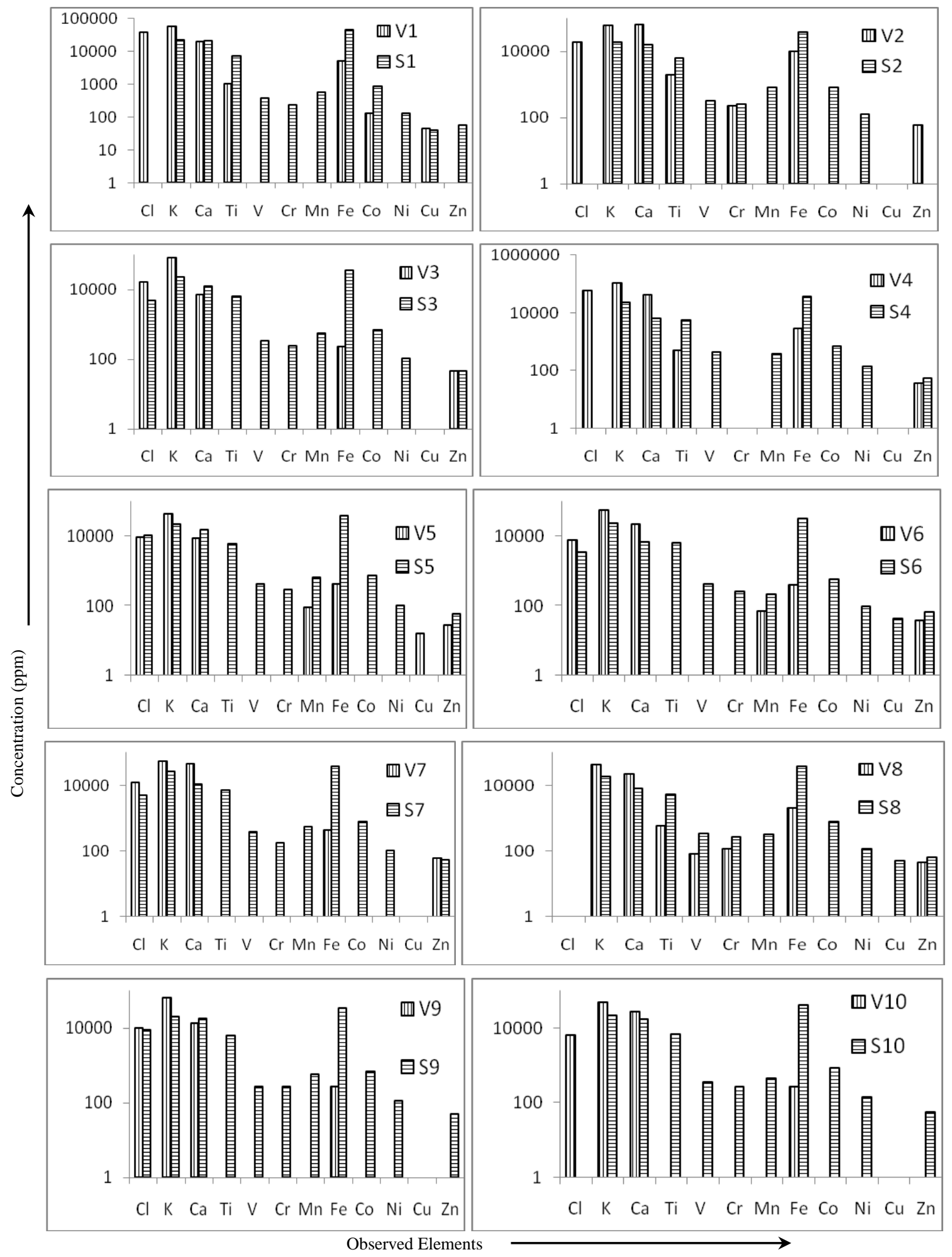

Fig. 3. Concentrations of different elements identified in soil and in the vegetable samples. 
TABLE II: CONCENTRATIONS (MG/KG) AND METAL/SOIL RATIOS IN DiFFERENT VEGETABLES

\begin{tabular}{|c|c|c|c|c|c|c|c|c|c|c|c|c|c|}
\hline $\begin{array}{l}\text { Leafy } \\
\text { vegetable }\end{array}$ & Part & Cl & $\mathbf{K}$ & $\mathrm{Ca}$ & $\mathbf{T i}$ & V & $\mathrm{Cr}$ & Mn & $\mathbf{F e}$ & Co & $\mathbf{N i}$ & $\mathrm{Cu}$ & Zn \\
\hline \multirow{3}{*}{$\begin{array}{l}\text { V1- } \\
\text { Water } \\
\text { spinach }\end{array}$} & Soil & ND & 22247 & 20990 & 7261 & 386.7 & 240 & "591.1 & $4 \quad 45820$ & 860.4 & 130.1 & 40.25 & $\overline{57.9}$ \\
\hline & Leaf & 39470 & 57889 & 20016 & 1042 & ND & ND & ND & 5204 & 132.5 & ND & 46.66 & ND \\
\hline & $\begin{array}{r}\text { Leaf/Soil } \\
(\%)\end{array}$ & IV & 260.2 & 95.4 & 14.4 & $\mathbf{0}$ & $\mathbf{0}$ & $\mathbf{0}$ & 11.4 & 15.4 & $\mathbf{0}$ & 115.9 & 0 \\
\hline \multirow{3}{*}{$\begin{array}{l}\text { V2- } \\
\text { Red } \\
\text { Spinach }\end{array}$} & Soil & ND & 20123 & 16506 & 6289 & 322.6 & 259.2 & 849.8 & 38554 & 842.9 & 128.4 & ND & $\mathrm{ND}$ \\
\hline & Leaf & 19396 & 63557 & 68365 & 2048 & ND & 238.8 & ND & 10171 & ND & ND & ND & 59.87 \\
\hline & $\begin{array}{r}\text { Leaf/Soil } \\
(\%) \\
\end{array}$ & IV & 315.8 & 414.2 & 32.6 & 0 & 92.1 & 0 & 26.4 & 0 & $\mathbf{0}$ & IV & IV \\
\hline \multicolumn{14}{|l|}{$\begin{array}{l}\text { Fruit } \\
\text { vegetable }\end{array}$} \\
\hline \multirow{3}{*}{$\begin{array}{l}\text { V3- } \\
\text { Lady's } \\
\text { finger }\end{array}$} & Soil & 5224 & 26694 & 10741 & 7107 & 383.3 & 185.8 & 2553.8 & 39353 & 826.2 & 106.4 & ND & 54.96 \\
\hline & Fruit & 12647 & 53730 & 46473 & ND & ND & ND & ND & 433.1 & ND & ND & ND & 62.03 \\
\hline & $\begin{array}{r}\text { Fruit/Soil } \\
(\%) \\
\end{array}$ & 242.1 & 201.3 & 432.7 & $\mathbf{0}$ & 0 & $\mathbf{0}$ & 0 & 1.1 & $\mathbf{0}$ & $\mathbf{0}$ & IV & 112.9 \\
\hline \multirow{3}{*}{$\begin{array}{l}\text { V4- } \\
\text { Snake } \\
\text { Gourd }\end{array}$} & Soil & ND & 18406 & 8201 & 5423 & 338.7 & 269.7 & 325.7 & 37922 & 823.3 & 120.2 & 52.75 & 66.9 \\
\hline & Fruit & ND & 44063 & 22316 & 609.4 & 80.93 & 122.1 & ND & 2067 & ND & ND & ND & 46.3 \\
\hline & $\begin{array}{r}\text { Fruit/Soil } \\
(\%) \\
\end{array}$ & IV & 239.4 & 272.1 & 11.2 & 23.9 & 45.3 & 0 & 5.5 & $\mathbf{0}$ & $\mathbf{0}$ & 0 & 69.1 \\
\hline \multirow{3}{*}{$\begin{array}{l}\text { V5- } \\
\text { Eggplant }\end{array}$} & Soil & 9270 & 20317 & 18149 & 6274 & 270.8 & 272.5 & 586.1 & 34568 & 693.5 & 115.1 & 0 & 52.62 \\
\hline & Fruit & 10209 & 66346 & 13943 & ND & ND & ND & ND & 274.9 & 0 & 0 & 0 & 0 \\
\hline & $\begin{array}{r}\text { Fruit/Soil } \\
(\%)\end{array}$ & 110.1 & 326.6 & 76.8 & 0 & 0 & 0 & 0 & 0.8 & 0 & 0 & IV & o \\
\hline \multirow{3}{*}{$\begin{array}{l}\text { V6- } \\
\text { Papaya }\end{array}$} & Soil & ND & 21735 & 17634 & 7102 & 356.7 & 277.8 & 467.3 & 41408 & 882.8 & 146.9 & 0 & 56.27 \\
\hline & Fruit & 6757 & 48601 & 27266 & ND & ND & ND & ND & 274.1 & ND & ND & ND & $\mathrm{ND}$ \\
\hline & $\begin{array}{r}\text { Fruit/Soil } \\
(\%) \\
\end{array}$ & IV & 223.6 & 154.6 & 0 & 0 & 0 & 0 & 0.7 & 0 & 0 & IV & 0 \\
\hline \multicolumn{14}{|c|}{$\begin{array}{l}\text { Root } \\
\text { vegetable } \\
\end{array}$} \\
\hline \multirow[t]{3}{*}{$\begin{array}{l}\text { V7- } \\
\text { Potato }\end{array}$} & Soil & "5090 & 23636 & 12523 & 6515 & 355.3 & 244.4 & "585 & 36536 & 734.9 & 108.3 & $\bar{~} 0$ & 48.1 \\
\hline & Root & 17097 & 82848 & 7383 & ND & ND & ND & ND & 237.2 & ND & ND & ND & 46.21 \\
\hline & $\begin{array}{r}\text { Root/Soil } \\
(\%)\end{array}$ & 335.9 & 350.5 & 58.9 & 0 & 0 & 0 & 0 & 0.65 & 0 & 0 & IV & 96.1 \\
\hline \multirow{3}{*}{$\begin{array}{l}\text { V8- } \\
\text { Radish }\end{array}$} & Soil & ND & 22865 & 6349 & 5757 & 441.7 & ND & 393.9 & 36742 & 728.1 & 141.1 & ND & 55.49 \\
\hline & Root & 60251 & 105964 & 41557 & 516.5 & ND & ND & ND & 2894 & ND & ND & ND & 36.2 \\
\hline & $\begin{array}{r}\text { Root/Soil } \\
(\%)\end{array}$ & IV & 463.4 & 654.5 & 8.9 & 0 & IV & 0 & 7.9 & 0 & 0 & IV & 65.2 \\
\hline \multirow{3}{*}{$\begin{array}{l}\text { V9- } \\
\text { Red } \\
\text { turnip }\end{array}$} & Soil & 10729 & 22935 & 15801 & 6323 & 423 & 298.6 & 652.9 & 38387 & 759.6 & 105.7 & ND & 60.3 \\
\hline & Root & 9335 & 45076 & 8994 & ND & ND & ND & 90.96 & 431.5 & ND & ND & 16.04 & 28.53 \\
\hline & $\begin{array}{r}\text { Root/Soil } \\
(\%) \\
\end{array}$ & 87.0 & 196.5 & 56.9 & 0 & 0 & 0 & 13.9 & 1.1 & 0 & 0 & IV & 47.3 \\
\hline \multirow{3}{*}{$\begin{array}{l}\text { V10- } \\
\text { Root } \\
\text { turnip }\end{array}$} & Soil & 3560 & 24453 & 6873 & 6419 & 442.7 & 264.4 & 215.7 & 32167 & 592.2 & 98.03 & 43.36 & 69.54 \\
\hline & Root & 8013 & 57521 & 23260 & ND & ND & ND & 70.45 & 399.7 & ND & ND & ND & 38.4 \\
\hline & $\begin{array}{r}\text { Root/Soil } \\
(\%)\end{array}$ & 225.1 & 235.2 & 338.4 & 0 & 0 & 0 & 32.6 & 1.2 & 0 & 0 & 0 & 55.2 \\
\hline
\end{tabular}

$\mathrm{ND}=$ not detected, IV = incalculable value

The interesting is the $\mathrm{Cr} / \mathrm{Fe}$ ratios in all soil samples are about 0.007 , which indicates that the mobilization of $\mathrm{Cr}$ is dependent on $\mathrm{Fe}$-content in soil. Although $\mathrm{Cr}$ is an essential element for humans, the hexavalent form of $\mathrm{Cr}$ is toxic. The wide spread of $\mathrm{Cr}$ in the environment poses a serious threat to human and animal welfare [13]. The toxicity of $\mathrm{Cr}$, however, is a function of oxidation state. Chromium exists in the environment in two stable oxidation states, namely $\mathrm{Cr}^{3+}$ and $\mathrm{Cr}^{6+}$. $\mathrm{Cr}^{6+}$ exists as chromate $\left(\mathrm{CrO}^{4-}\right)$ is easily soluble in soils and ground water, and trends to be mobile in the environment. On the other hand, $\mathrm{Cr}^{3+}$ forms complex with soil minerals, which are insoluble [14]. Within soils, $\mathrm{Fe}^{2+}$ and sulfide $\left(\mathrm{S}^{2-}\right)$ control the redox status of chromium [15]. In the homogeneous system, $\mathrm{Fe}^{2+}$ serves as a catalyst for the reaction, 
i.e., $\mathrm{Cr}^{6+}$ is reduced by $\mathrm{Fe}^{2+}$ to form $\mathrm{Fe}^{3+}$, which is then reduced by sulfide to regenerate $\mathrm{Fe}^{2+}$, enhancing the overall rate of $\mathrm{Cr}^{6+}$ reduction. The ultimate way of $\mathrm{Cr}^{6+}$ reduction is of considerable pragmatic importance because it dictates the reactivity of reduced $\mathrm{Cr}^{3+}$ in the environment. The solubility of $\mathrm{Cr}^{3+}$ is proportional to the ratio of $\mathrm{Cr}^{3+}$ to $\mathrm{Fe}^{3+}$, with increased quantities of $\mathrm{Fe}^{3+}$ stabilizing the solid [14]. Mechanisms under which $\mathrm{Cr}^{3+}$ could be remobilized are dependent upon the solid phase speciation and co-association of $\mathrm{Cr}$ with other soil constituents.

Nickel does not form insoluble precipitates in unpolluted soils and retention for $\mathrm{Ni}$ is, therefore, exclusively through absorption mechanisms. Nickel will absorb to clays, iron, manganese oxides and organic matter and is thus removed from the soil solution. The formation of complexes of $\mathrm{Ni}$ with both inorganic and organic ligands will increase Ni mobility in soils. As and $\mathrm{Pb}$ are a matter of serious concern because of they are carcinogenic, toxic at very low concentrations and bioaccumulative in organisms. Automobile emissions are considerable source of heavy metals, especially $\mathrm{Pb}$ in the soil. In the present study $\mathrm{As}$ and $\mathrm{Pb}$ were not found in any samples signifies that the soils are not contaminated by these metal.

\section{B. Elements in Vegetable Samples}

The selected vegetables were cultivated in the same area of soil samples. The vegetable samples were also analyzed by PIXE technique. The relative mass concentrations identified in vegetable samples are shown in Fig. 2. Wide ranges of elemental contents were observed among the studied specimens. Most of the elements in vegetables are found in less concentration than soil indicating their lesser transmission from soil to plant. $\mathrm{K}$ and $\mathrm{Ca}$ are found the most abundant detected elements (major) in the samples. $\mathrm{K}$ is crucial to heart function [16] and $\mathrm{Ca}$ is an essential element for maintaining healthy bones and teeth. The Fe content is also fairly good in the entire samples. Fe deficiency can causes anemia. $\mathrm{Cl}$ was identified almost in all vegetables samples; this could be due to saline water used for irrigation and the vegetables are grown in saline soil. $\mathrm{NaCl}$ and $\mathrm{Na}(\mathrm{NaCl})_{n}$ characterize the marine salt. Thus $\mathrm{NaCl}$ from marine aerosol was deposited on leaves and absorbed by vegetables. V observed only in V8 could be from the ore or from anthropogenic source (burning of crude oil) [12].

Heavy metals such as $\mathrm{Cr}, \mathrm{Mn}, \mathrm{Co}, \mathrm{Cu}$ and $\mathrm{Zn}$ were found in some different samples. Cr was detected in V2 and V8 at high amount $238.8 \mathrm{ppm}$ and $122.1 \mathrm{ppm}$ respectively that exceed the toxic level (5-30 ppm) [10]. Co was found only in V1 with concentration $132.5 \mathrm{ppm}$ which also more than toxic level (15-50 ppm) [10]. These required some attention. $\mathrm{Ni}$ and $\mathrm{Pb}$ were not found in any vegetable samples under study. Mn and $\mathrm{Zn}$ contents are found in some samples with good amount but below toxic levels [10]. Ga, Ge, As and $\mathrm{Br}$ were not identified in vegetable samples indicating that any agro chemical product had not been used. Vegetables are one of the key sources of mineral elements. Excess or lack of mineral elements in vegetables may cause serious disorder in human health and people may suffer from various diseases. The result shows that most of the investigated vegetables contain elements of vital importance in man's metabolism and that are needed for growth and developments, prevention and healing of diseases.

\section{Elements Uptake from Soil to Vegetable}

When growing edible vegetables or crops in contaminated soils, it is important to know the extent of accumulation in plants and their different parts. In order to study the metal uptake by vegetables from the study area, we selected species which are most frequently grown and commonly consumed by population in the region. The elemental mass concentrations of elements identified in soil and vegetable are shown in Fig. 3. The analysis of the vegetable and soil samples show that the $\mathrm{K}$, $\mathrm{Ca}$ and $\mathrm{Fe}$ present in all soils were absorbed by all the vegetables. The $\mathrm{Cl}$ present in soil S3, S5, S6, S7 and S9 were also absorbed by the vegetables. Additional $\mathrm{Cl}$ was observed in vegetables V1, V2, V4 and V10 were not present in the soil. Heavy metals Cr, Co and Ni present in 6 soils (S3, S5, S6, S7, S9 and S10) were not absorbed by the vegetables. Mn was present in all soils but only absorbed by the vegetables V5 and V6. The elements not identified in vegetables could not be biologically available in soils or they could be absorbed in very low concentration (less than $1 \mathrm{ng} / \mathrm{g}$ ). On the other hand the elements not identified in soils but present in vegetables could be absorbed from water or fertilizer or pesticides used during cultivation or contained in the airborne particles deposited on the leaves [12].

Table II represents the uptake of metals from soil to vegetables. For low $\mathrm{Z}$ elements the uptake is very high $(\mathrm{Cl}$ from $87.0-335.9 \%, \mathrm{~K}$ from $196.5-463.4 \%$, Ca from $76.8-654.5 \%$ ) than heavy metals, which specifying their easy mobilization. For $\mathrm{Fe}$, the uptake variation is small (0.65-26.4\%). Although $\mathrm{Cr}$, Co and $\mathrm{Ni}$ are found in high concentrations in soils but their uptake by vegetables is very low. Cr uptake was found only in two vegetable samples, V2 and V4, but with great amount $(92.1 \%$ and $45.3 \%$ respectively). Co was uptake only by V1 with $11.4 \%$ whereas $\mathrm{Ni}$ was not uptake by any vegetables in the present study. $\mathrm{Zn}$ is readily absorbed showing the highest $(112.9 \%)$ uptake than all heavy metals ranging from $47.3-112.9 \%$.

\section{CONCLUSION}

In the last few years, nuclear techniques have made an important contribution in the field of elemental analysis of environmental samples. Elemental contents in soils and vegetables are an important characteristic in environmental monitoring essential for human health. In this study, the application of PIXE technique allows the identification of metals present in soil and in the vegetables collected from selected saline region of Bangladesh. Vegetables can absorb metals from different sources, but this absorption depends on the metal chemical form. The results from the study show that low $\mathrm{Z}$ elements are easily accumulate to vegetables with high amount. $\mathrm{Cl}$ was observed in almost all vegetables at significant amount accrued from the soil as well as from irrigation water and marine aerosol deposited on leaves, representing the samples were collected from sea shore area. Some heavy elements such as $\mathrm{Cr}$, $\mathrm{Co}$ and $\mathrm{Ni}$ are present at levels considered potentially hazardous in soils. Among them $\mathrm{Cr}$ and $\mathrm{Co}$ are transfer to some vegetables at levels that exceed those considered as toxic. This needed further examined 
because of long term effect of these metals on human health. Finally this methodology can be considered convenient for identifying the possible sources of metals in environmental soil and vegetable samples.

\section{ACKNOWLEDGMENT}

The authors like to thank the staff of Tandem Accelerator, Savar, Dhaka, for their help in preparation of samples and irradiation.

\section{REFERENCES}

[1] J. Puolanne, O. Pyy, and U. Jeltsch, Contaminated Soil Site Survey and Remediation Project, Ministry of the environment, Finnish Printing Centre, Helsinki, 1994.

[2] A. Kabata-Pendias and C. A. Domy, Soil Amendments and Environmental Quality, in Florida, 1995, ch. 4, p. 50.

[3] S. A. Haque, "Salinity problems and crop production in coastal regions of Bangladesh," Pak. J. Bot., vol. 38, no. 5, pp.1359-1365, 2006.

[4] L. Petersen and S. Shireen, "Soil and water salinity in the coastal area of Bangladesh,” SRDI, pp. 70-79, 2001

[5] Z. Karim, S. G. Hussain, and M. Ahmed, "Salinity problems and crop intensification in the coastal regions of Bangladesh," Soils Publication No. 33. BARC, pp. 17-25, 1990.

[6] E. Berman, Toxic Metals and Their Analysis, Heyden, London, 1980.

[7] R. Bock, A Handbook of Decomposition Methods in Analytical Chemistry, Edinburgh: International Text book Company, 1979.

[8] J. A. Maxwell, W. J. Teesdale, and J. L. Campbell, "The guelph PIXE software package II," Nucl. Inst. and Meth. B, vol. 95, pp. 407-421, 1995, January 21, 2014.

[9] J. L. Campbell, D. Highuchi, J. A. Maxwell, and W. J. Teesdale, "Quantitative PIXE microanalysis of thick specimens," Nucl. Inst. and Meth. B, vol. 77, pp. 95-109, 1993.

[10] K. Pendias and H. Pendias, Trace Elements in Soils and Plants, CRC Press, Boca Raton, FL, 2001

[11] F. W. Field and P. J. Haines, Environmental Analytical Chemistry, Blackie Academic and Professional, London, p. 424, 1995.

[12] K. D. da Cunha, J. Cazicava, M. J. Coelho, and C. V. B. Leite, "PIXE, ${ }^{252} \mathrm{Cf}-\mathrm{PDMS}$ and radiochemistry applied for soil and vegetable analysis," Nucl. Inst. and Meth. B, vol. 243, pp. 179-186, 2006.

[13] N. Pundyte, E. Baltrenaite, P. Pereira, and D. Paliulis, "Anthropogenic effects on heavy metals and macronutrients accumulation in soil and wood of PinusSylvestris," J. Envi. Engi. and Landscape Management, vol. 19, pp. 34-40, 2011.

[14] B. M. Sass and D. Rai, "Solubility of amorphous chromium(IIl)-iron(III) hydroxide solid solutions," Inorg. Chem., vol. 26, pp. 2228-2232, 1987.

[15] C. M. Hansel, B. W. Wielinga, and S. Fendorf, "Structural and compositional evolution of $\mathrm{Cr} / \mathrm{Fe}$ solids following indirect chromate reduction by dissimilatory iron-reducing bacteria," Geochim. Cosmochim. Acta, vol. 67, pp. 401-412, 2003.

[16] British Medical Journal, vol. 1, pp. 469-470, 1977.

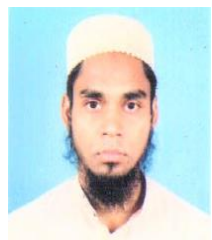

M. R. Rahman received the master degree in physics from Jahangirnagar University, Dhaka, Bangladesh in 2004. He is an assistant professor of physics discipline of Khulna University, Khulna, Bangladesh and now he is doing the Ph.D from Department of Physics, Jahangirnagar University, Dhaka, Bangladesh with joint supervision by Prof. Dr. Mohammad Obaidur Rahman of Department of Physics, Jahangirnagar University and Dr. Md. Asad Shariff, Principal Scientific Officer \& Head of Tandem Accelerator Facilities Division, Institute of Nuclear Science \& Technology, Atomic Energy Research Establishment, Bangladesh Atomic Energy Commission (BAEC).

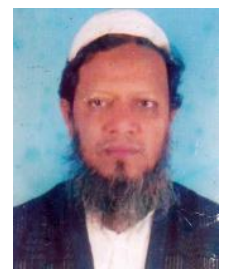

M. O. Rahman received the master degree in physics from Jahangirnagar University, Dhaka, Bangladesh in 1988. He received the DICTP degree from International Centre for Theoretical Physics (ICTP), Trieste, Italy in 1993. He also received the Ph.D. degree in material structural science from Graduate University of Advance Studies, Japan in 2002. Now, he is a professor of Department of Physics, Jahangirnagar University, Dhaka, Bangladesh. He has done several experiments at ELETTRA, Italy; DESY, Germany Synchrotron Radiation Laboratory and Joseph Stefan Institute Ljubljana, Slovenia on EXAFS (Extended X-ray Absorption Fine Structure) and X-ray optics. At present he is supervising M. Phil. and the $\mathrm{Ph} . \mathrm{D}$. students with collaboration through BAEC, BCSIR and Department of Physics, Jahangirnagar University using PIXE, PIGE, XRD and other techniques.

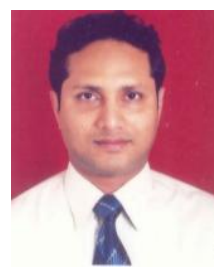

M. A. Shariff received the master degree in physics from University of Dhaka, Bangladesh in 1990. He received the doctor degree in nuclear engineering from Lund University, Lund, Sweden in 2004. During his Ph.D work two new state of the art beam lines, for performing experiments using ion beams of different size, have been designed and constructed at the Lund nuclear microprobe (NMP) accelerator laboratory, nuclear physics division, Department of physics, Lund university, Sweden. Now he is a principal scientific officer and the head of Tandem Accelerator Facilities Division, Institute of Nuclear Science \& Technology, Atomic Energy Research Establishment, Bangladesh Atomic Energy Commission (BAEC). He was the key person for commissioning and testing of Tandem Accelerator at BAEC. At present the facility is operational and various types (soil, vegetable, plant, human blood, coal, cement, chicken, etc.) of sample analysis using particle induced $\mathrm{x}$-ray emission (PIXE) technique are going on. His specialty is nuclear physics and accelerator technology.

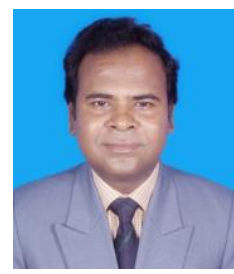

M. S. Uddin received the master degree in applied chemistry from Rajshahi University, Rajshahai, Bangladesh in 1993. He received the M.Phil. degree in nuclear science from that university in 2002 . He is also received the doctor degree in nuclear science from Tohoku University, Japan in 2005. Now he is the principal scientific officer, Tandem Accelerator Facilities Division, Institute of Nuclear Science \& Technology, Atomic Energy Research Establishment, Bangladesh Atomic Energy Commission (BAEC).

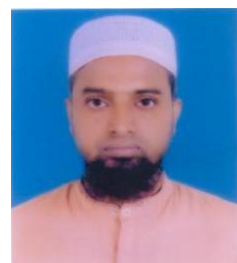

M. M. Hasan received the master degree in applied physics, electronics and communication enginnering from Islamic University, Kushtia, Bangladesh in 2004. He is currently a senior scientific officer at Tandem Accelerator Facilities Division, Institute of Nuclear Science \& Technology, Atomic Energy Research Establishment, Bangladesh Atomic Energy Commission (BAEC). He has good experience on maintenance, operation and development of accelerator at Bangladesh Atomic Energy Commission for elemental analysis using Ion Beam Technique.

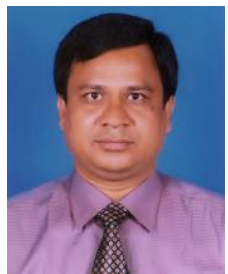

M. A. Shameem received the master degree of engineering from East West University, Bangladesh Now he is a senior engineer at Tandem Accelerator Facilities Division, Institute of Nuclear Science \& Technology, Atomic Energy Research Establishment, Bangladesh Atomic Energy Commission (BAEC). 